\title{
Wind tunnel tests of tent halls of different shape
}

\author{
Agnieszka Porowska ${ }^{1, *}$, Renata Kłaput $^{1}$ and Andrzej Flaga ${ }^{1}$ \\ ${ }^{1}$ Wind Engineering Laboratory, Cracow University of Technology, Poland
}

\begin{abstract}
Aerodynamic investigations of wind pressure distribution on the surfaces of models of tent halls were carried out in the boundary layer wind tunnel at the Cracow University of Technology. Four types of objects of different shapes and construction were tested. Although tent halls are significantly vulnerable with respect to the wind action, there is no information about pressure distribution on objects of such type in standards, codes and normalization documents. Obtained results indicate that it is necessary to take into account different configurations of wind action while designing of the analysed structures.
\end{abstract}

\section{Introduction}

Four tent halls of different shape were tested in the Wind Engineering Laboratory at the Cracow University of Technology [1]. Tent halls are light buildings which are usually located in open space areas where wind velocities are high. For this reason they are vulnerable with respect to the wind action on them. Additionally, European standards do not provide enough information about this issue [2]. Construction of the roofs of tested halls does not fulfil a criterion of a gable or flat roof in accordance with [2]. Only one of them can be categorized as an arched roof, but [2] considers just the case of wind blowing perpendicular to the structure and the dependency on an angle of wind onflow is not taken into account. In this situation, wind tunnel investigations of uncommon structures are recommended.

Problem of wind pressure distribution on low-rise buildings was undertaken by many researchers, starting from pioneering works of Davenport [3,4]. In these wind-tunnel tests models of different geometry and the influence of boundary layer and turbulence were investigated. Then the methods of codification of these results in the form of area-averaged pressure coefficient were elaborated [5]. However, there was still necessity to improve this area of knowledge, because of the development of the structures complexity and vulnerability. Therefore researchers studied influence of different parameters such as relative building height [6] or length [7] on wind pressure distribution on its surface. Also comparisons of full-scale and wind tunnel tests were already made [8]. Results of experiments carried out on models and calculations with accordance to the different standards were compared in $[7,9,10]$. Moreover, in many review papers $[11,12,13]$ wind pressure distribution on buildings of varying shape was discussed. Up to now this issue is under consideration and there are still problems which need to be investigated thoroughly

\footnotetext{
*Corresponding author: agnieszkaporowska89@gmail.com
} 
such as influence of roof shape or angle of wind onflow on wind pressure distribution on the external surfaces of low-rise buildings.

The aim of this work is to show that during the design process of atypical structures it is necessary to take into account different angles of wind attack and consider the most unfavourable ones. It is important, especially in the case of tent halls which are highly exposed to wind action.

\section{Description of the research}

\subsection{Simulation of the boundary layer}

The experiments on the models of tent-halls were carried out in the boundary layer wind tunnel. In the initial part of the investigations, a structure of wind flow was determined. Thermo-anemometers were used to measure mean as well as fluctuation of wind velocity in 6 points located in the working section of the wind tunnel on the height from $5 \mathrm{~cm}$ to $30 \mathrm{~cm}$ above the floor level. On the basis of the data received from measurements, mean wind velocity profile was obtained with use of the following power-low form:

$$
V(z)=V_{r e f}\left(z / z_{r e f}\right)^{\alpha}
$$

where: $z_{\text {ref }}=0.3 \mathrm{~m}-$ reference height; $V_{\text {ref }}=14.7 \mathrm{~m} / \mathrm{s}-$ reference velocity (mean wind velocity at the reference height); $\alpha=0.18$ - wind profile exponent dependent on the terrain roughness.

Obtained wind profile is shown in Fig.1a. Points mark values obtained in the wind tunnel tests and line marks function determined by least-square regression. This profile corresponds with $2^{\text {nd }}$ terrain category with respect to [2] and complies with assumptions concerning wind conditions characteristic for destined localization of investigated tent halls. Turbulence intensity on the reference height was about $16 \%$. Tests were carried out for 8 angles of wind attack with increment of $45^{\circ}$. Fig. $1 \mathrm{~b}$ shows orientation of the model with respect to the adopted wind directions.

a)

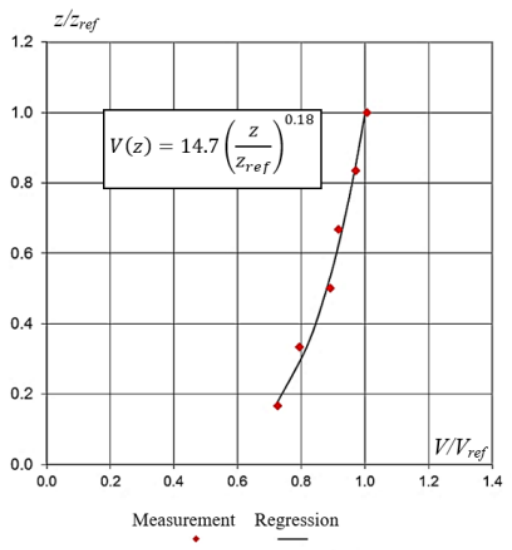

b)

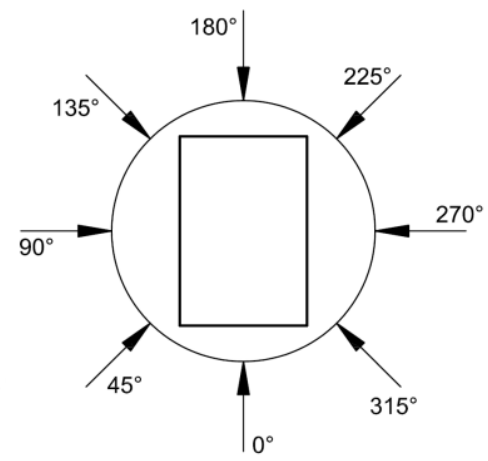

Fig. 1. Wind tunnel tests: mean wind velocity profile (a), angles of wind attack with respect to the tent hall orientation (b). 


\subsection{Description of the wind tunnel tests}

Investigations were conducted on the models of four tent halls designated as $\mathrm{H} 1, \mathrm{H} 2, \mathrm{H} 3$ and $\mathrm{H} 4$ for the simplification. Fig. 2 shows schemes of all four models with the localization of the measurement points and cross-sections.

$\mathrm{H} 1$
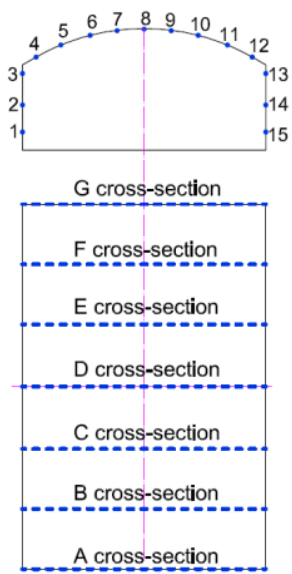

$\mathrm{H} 2$
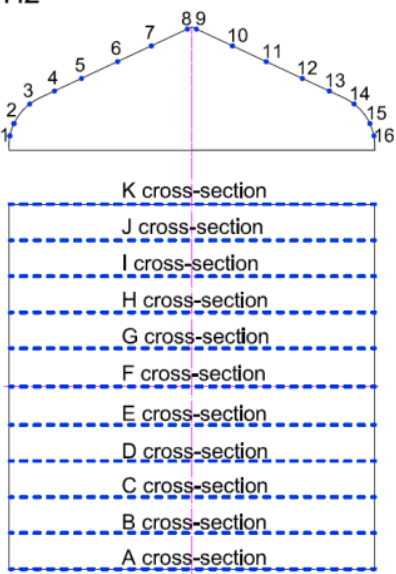

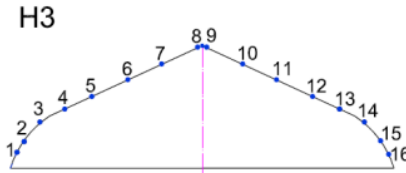

K cross-section

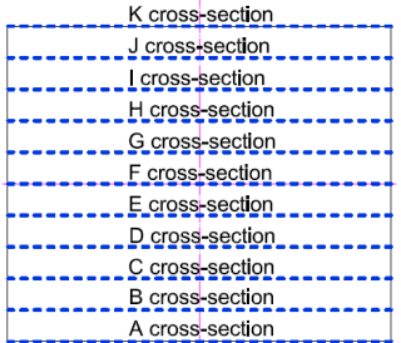

$\mathrm{H} 4$
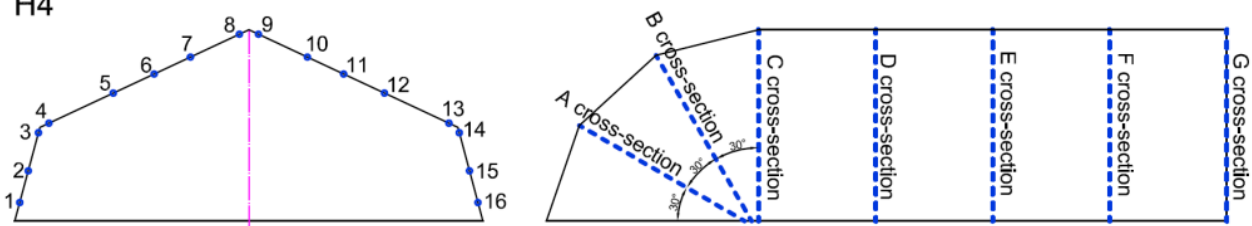

Fig. 2. Scheme of four tent halls H1-H4: distribution of the measurement points in the cross section and localization of the cross-sections on the scheme of the hall in the top view $(\mathrm{H} 1-\mathrm{H} 3)$ or in the side view (H4).

Wind pressure was measured in points located in the cross-sections with use of the system of pressure electronic scanners of parallel type. Wind velocity reference pressure was determined in the reference point in the area of undisturbed wind flow in the front of the model. As a result external mean wind pressure coefficient was obtained, which was defined as:

$$
C_{p e}=p_{e} / \mathrm{q}_{r e f}
$$

where: $p_{e}-$ mean wind pressure measured on the external surface of the object (positive values - positive pressure, negative values - negative pressure); $\mathrm{q}_{r e f}$ - reference pressure.

\section{Results of the wind tunnel tests}

Following diagrams show results of the investigations as the mean external pressure coefficients determined in the measurement points on the cross-sections of four halls. For simplification of the data presentation, halls cross-sections were divided into three categories which are summarized in Table 1. Because of the model symmetry, it was decided that results will be presented only for angles of wind onflow in the following range: $0^{\circ}-180^{\circ}$, but for the whole of the respective cross-sections. 
Table 1. Cross-section categories adopted in the result presentation.

\begin{tabular}{|c|c|c|c|c|}
\hline Name of hall & H1 & H2 & H3 & H4 \\
\hline Cross-section category & \multicolumn{4}{|c|}{ Name of a cross-section } \\
\hline Marginal & A, G & A, K & A, K & A, G \\
\hline Intermediate & B, C, E, F & B-E, G-J & B-E, G-J & B \\
\hline Middle & D & F & F & C-F \\
\hline
\end{tabular}

Results for one of marginal, intermediate and middle cross-sections are presented for each of the tent halls with exception of $\mathrm{H} 4$-where two marginal cross-sections were taken into account because of specific geometry of the tent hall. In the analysis of the results, the angles of wind onflow for which the maximum values of mean external wind pressure coefficients were obtained are defined as unfavourable angles.

Results for $\mathrm{H} 1$ are shown in Fig. 3.
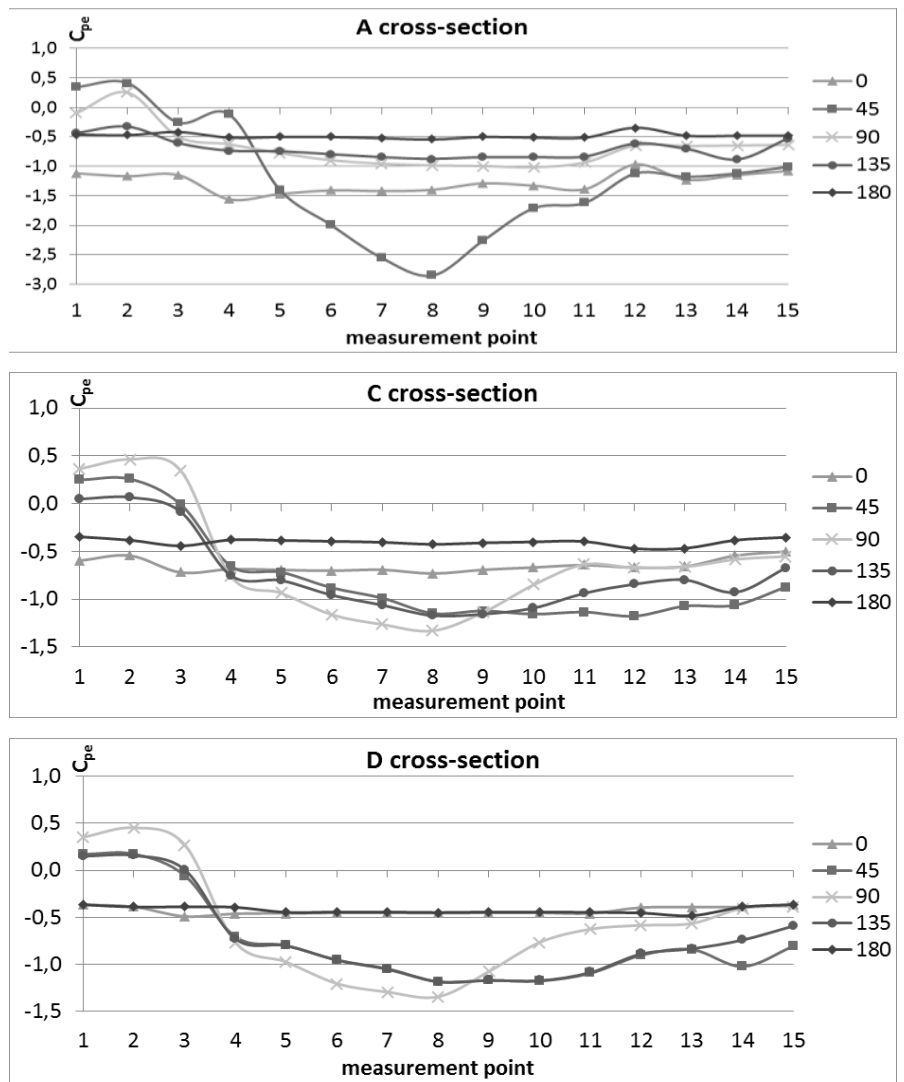

Fig. 3. Mean external wind pressure coefficients obtained for H1.

On the basis of the results for $\mathrm{H} 1$ one can draw the following conclusions:

1. The highest negative pressure appears in the middle part (points 7-8) of all of the crosssections and maximum negative pressure occurs on the edge of the hall length (crosssections: $A, G)$;

2. The highest positive pressures appear on the side-walls of all of the cross sections (points: 1, 2) and regardless of the cross-section location on the length of hall maximum positive pressure is at the same level $\left(C_{p e}\right.$ about 0.5$)$;

3. The most unfavourable angles of wind attack are as follows: marginal cross-sections $45^{\circ}$; intermediate cross-sections $-90^{\circ}, 45^{\circ}$ and $135^{\circ}$; middle cross-section $-90^{\circ}$ but for 
the wall part of the cross-section on the leeward side (points 13-15) angles $45^{\circ}$ and $135^{\circ}$ are worse.

Diagrams for $\mathrm{H} 2$ and $\mathrm{H} 3$ are presented in fig. 4 and Fig. 5, respectively.
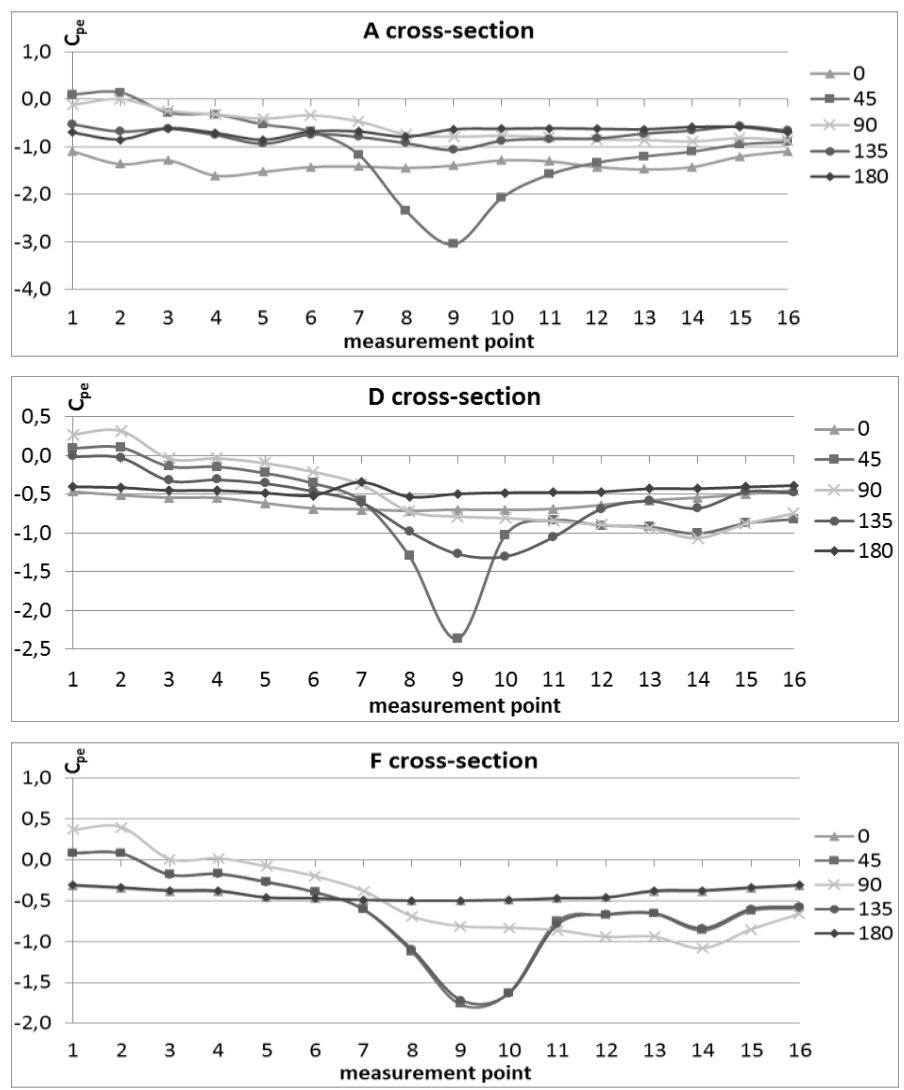

Fig. 4. Mean external wind pressure coefficients obtained for H2.
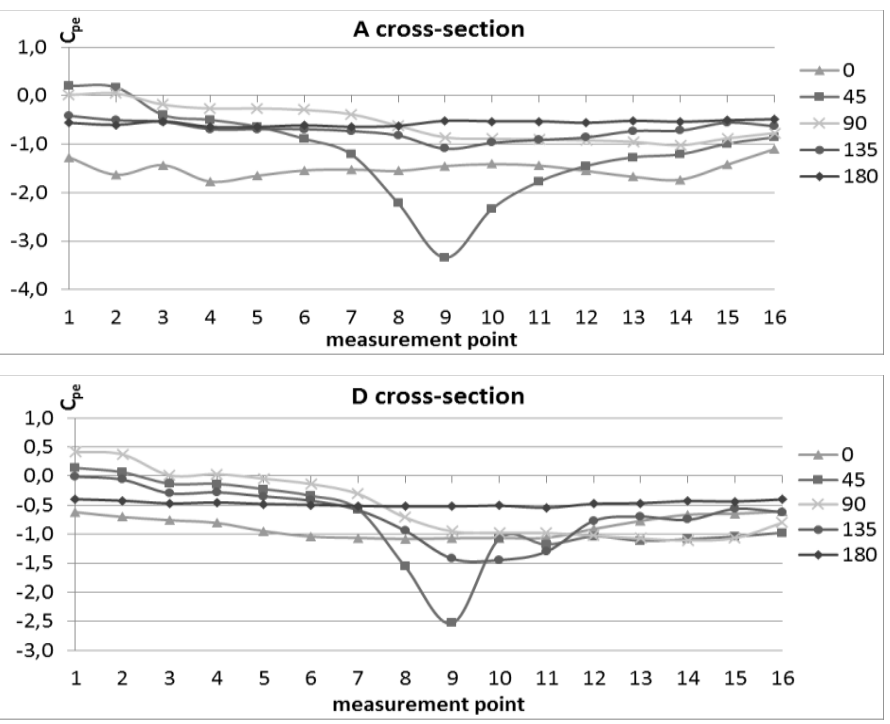


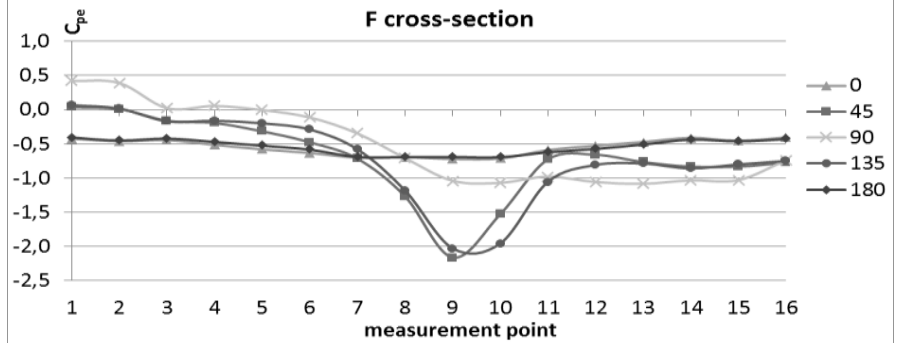

Fig. 5. Mean external wind pressure coefficients obtained for H3.

Results for $\mathrm{H} 2$ and $\mathrm{H} 3$ are similar, so conclusions for both of them are presented togheter:

1. The highest negative pressure appears in the middle (points 8-10) of all of the crosssections and maximum negative pressure occurs on the edge of the hall length (crosssections: A, K);

2. The highest positive pressures appear on the side-walls of all of the cross sections (points: 1, 2) and it is higher for cross-section in the middle of hall length (F crosssection);

3. The most unfavourable angles of wind attack are as follows: marginal and intermediate cross-sections $-45^{\circ}$, middle cross-sections $-45^{\circ}, 135^{\circ}$.

Results for $\mathrm{H} 4$ are shown in Fig. 6.
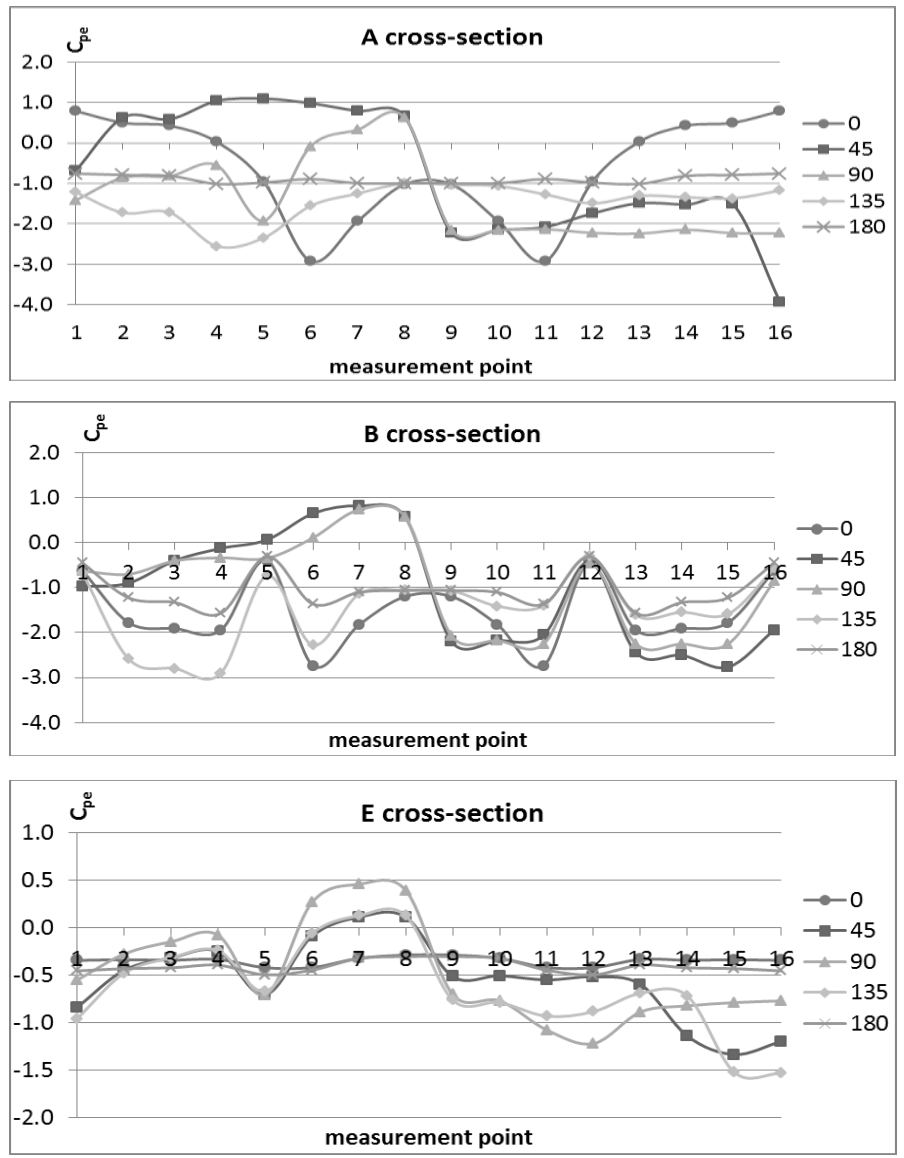


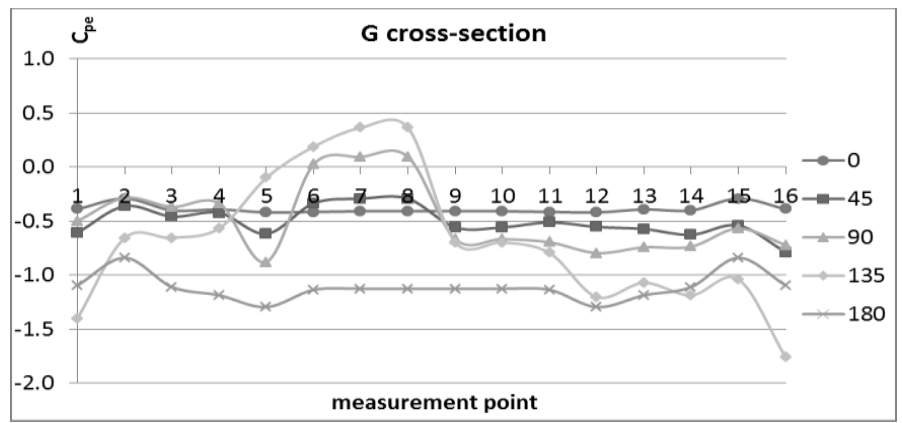

Fig. 6. Mean external wind pressure coefficients obtained for $\mathrm{H} 4$.

On the basis of the results obtained for $\mathrm{H} 4$, the following remarks can be presented:

1. Maximal negative pressures and positive pressures appear in the inclined crosssections (A,B);

2. The highest negative pressures can be seen in the following parts of the crosssections:

- A cross-section: high dependency on the angle of wind onflow,

- B cross-section: the middle and upper part of the wall (points 2-4 for the angle $135^{\circ}$ and 13-16 for the angle $45^{\circ}$ ),

- C-G cross-sections: the lower part of the wall (points 1,2 and 15,16) for the angle $135^{\circ}$;

3. The highest positive pressures appear in the following parts of the cross-sections:

- A cross-section: high dependency on the angle of wind onflow,

- B-G cross-sections: in the middle and in the upper part of the roof (points 6-8),

\section{General conclusions}

The range of the mean external wind pressure coefficient for four halls is summarized in Table 2 .

Table 2. The range of the mean external wind pressure coefficient $C_{p e}$.

\begin{tabular}{|c|c|c|c|c|c|c|c|c|}
\hline Name of hall & \multicolumn{2}{|c|}{ H1 } & \multicolumn{2}{c|}{ H2 } & \multicolumn{2}{c|}{ H3 } & \multicolumn{2}{c|}{ H4 } \\
\hline $\begin{array}{c}\text { Cross-section } \\
\text { category }\end{array}$ & $C_{p e, \min }$ & $C_{p e, \max }$ & $C_{p e, \min }$ & $C_{p e, \max }$ & $C_{p e, \min }$ & $C_{p e, \max }$ & $C_{p e, \min }$ & $C_{p e, \max }$ \\
\hline $\begin{array}{c}\text { Marginal cross- } \\
\text { sections }\end{array}$ & -3.0 & 0.5 & -4.0 & 0.3 & -4.0 & 0.4 & -4.0 & 1.0 \\
\hline $\begin{array}{c}\text { Intermediate } \\
\text { cross-sections }\end{array}$ & -1.5 & 0.5 & -3.0 & 0.4 & -3.3 & 0.45 & -3.0 & 1.1 \\
\hline $\begin{array}{c}\text { Middle } \\
\text { cross-sections }\end{array}$ & -1.4 & 0.4 & -2.0 & 0.45 & -2.5 & 0.5 & -2.0 & 0.5 \\
\hline
\end{tabular}

It can be observed that maximum wind negative pressure appears in the marginal crosssection for all of the analysed halls. For three of them: $\mathrm{H} 1-\mathrm{H} 3$, maximum negative pressure occurs in the half of the cross-section (H1: points 7-9, H2, H3: points 8-10). H4 presents slightly different results because the highest negative pressures can be noticed in the lower part of the wall (points 1-4).

Mean external wind pressure coefficient has extreme values for the following angles of wind onflow for particular halls: 
- H1: $90^{\circ}$ for middle and intermediate cross-sections, but $45^{\circ}$ for marginal crosssections. It is worth to point out that values of $C_{p e}$ in marginal cross-section are significantly higher than in the middle and itermediate cross-sections,

- $\mathrm{H} 2, \mathrm{H} 3: 45^{\circ}$ for all of the cross-sections,

- H4: $45^{\circ}$ and $135^{\circ}$ for inclined cross-sections (A, B), $90^{\circ}$ and $135^{\circ}$ for other crosssections.

During the analysis of the results one can also notice differences appearing for $C_{p e}$ for $\mathrm{H} 2$ and $\mathrm{H} 3$. These halls have similar geometry, but they differ only in the length, wherein $\mathrm{H} 2$ is longer than H3. Negative pressure for H3 is higher than for $\mathrm{H} 2$ and this trend is visible in results for all of the cross-sections. It can be concluded that length of hall has influence on mean external wind pressure coefficient: the smaller length, the higher value of $C_{p e}$. Especially, it is seen in marginal cross-section where the differnce is up to 0,5 . It would be necessary to analyse this dependency thoroughly.

To summarise, in most of the analysed cases the extremal mean wind pressure coefficient appears at the heighest point of the roof of the marginal cross-section of tent halls. The shape of the hall cross-section has significant infuence on the value of this coefficient. The highest vallues of $C_{p e}$ appears for $45^{\circ}$ angle of wind onflow, so it is essential to take into consideration this information in the process of design of such structures.

This work was sponsored by Rekord Hale Namiotowe Sp. z o.o.

\section{References}

1. A. Flaga, R. Kłaput, A. Porowska, Ł. Flaga, M. Mańczyk. Aerodynamic investigations and design of the construction of four tent halls of the company REKORD HALE NAMIOTOWE Sp. z o.o., Cracow, (Technical Report, in polish, 2015)

2. PN-EN 1991-1-4, 2008. Eurocode 1 (2008)

3. A.G. Davenport, D. Surry, T. Stathopoulos. Wind Loads on Low-Rise Buildings. The University of Western Ontario, London, Ontario, Canada (Final Report on Phases I and II. BLWT-SS7, 1977)

4. A.G. Davenport, D. Surry, T. Stathopoulos. Wind Loads on Low-Rise Buildings. The University of Western Ontario, London, Ontario, Canada (Final Report on Phase III. BLWT-SS8, 1978)

5. D. Surry, T. Stathopoulos, J. Wind Eng. Ind. Aerodyn. 2, 4, 385-397 (1978)

6. H.J. Gerhardt, C. Kramer, J. Wind Eng. Ind. Aerodyn. 43, 1765-1773 (1992)

7. H. Alrawashdeh, T. Stathopoulos, J. Wind Eng. Ind. Aerodyn 147, 212-225 (2015)

8. R.V. Milford, A.M. Goliger, J.L. Waldech, J. Wind Eng. Ind. Aerodyn. 43, 1693-1704 (1992)

9. E. Gavanski, Y. Uematsu, J. Wind Eng. Ind. Aerodyn. 132, 77-91 (2014)

10. L.M. St Pierre, G.A. Kopp, D. Surry, T.C.E. Ho, J. Wind Eng. Ind. Aerodyn. 93, 31-59 (2005)

11. T. Stathopoulos, Eng. Struct. 6, 119-135 (1984)

12. H.W. Tieleman, J. Wind Eng. Ind. Aerodyn. 91, 1627-1649 (2003)

13. T.C.E. Ho, D. Surry, D. Morrish, G.A. Kopp, J. Wind Eng. Ind. Aerodyn. 93, 1-30 (2005) 